\title{
Raising Wages as a Strategy to Reduce Corruption
}

\author{
Hideki Sato \\ Faculty of Economics, Kyushu Sangyo University \\ 2-3-1, Matsukadai, Higashi, Fukuoka 813-8503, Japan \\ Tel: +81-092-673-5211Ｅ-mail: hsato@ip.kyusan-u.ac.jp
}

Received: September 27, 2011

Accepted: October 7, 2011 Published: December 15, 2011

doi:10.5430/jms.v2n4p56

URL: http://dx.doi.org/10.5430/jms.v2n4p56

\begin{abstract}
This paper examines whether raising the salaries of government tax auditors reduces their incentive to accept bribes. It evaluates an optimal tax structure and economic welfare under conditions of perfect and imperfect information in relation to conditions for bribery. The major policy implication of this paper is that it is not necessarily desirable to increase salaries as an anticorruption measure. Even if government can reduce corruption by improving civil servants' pay, obtaining funds to do so by raising the income tax will worsen economic welfare, based on the optimal tax structure.
\end{abstract}

Keywords: Anticorruption, Wages, Optimal Tax, Tax Evasion

\section{Introduction}

Under its “National Strategy for Preventing and Combating Corruption toward 2020," the Vietnamese government committed to raising the wages of civil servants in an effort to prevent corruption. The idea that low wages encourage corruption has been accepted as conventional wisdom since Myrdal (1968). Using the example of income tax collection, this paper will show that, in terms of financial resources, improving the wages of public officials to prevent corruption may not be socially desirable. In particular, we show that economic welfare is not enhanced if government raises income taxes in order to fund such wages.

Among studies of corruption in tax administration, with respect to which Virmani (1987) is a pioneering work, contemporary research customarily adopts the hierarchical structure model (tax auditor-super auditor-taxpayers) articulated by Singh (2008). This paper applies agency theory to this three-layer configuration, identified here as government-tax auditor-taxpayers, to derive the optimal tax structure. Several implications arise from applying agency theory to derive an optimal tax structure. When government commits itself to a given policy, it acts as a Stackelberg leader as an element in a strategic interdependence with taxpayers, whom the policy motivates to react in an optimum way. By using agency theory, it is possible to derive the optimum policies to which government should be committed.

The issue of corruption has not been considered in previous studies of income tax grounded in agency theory (for example, Reinganum \& Wilde (1985), Border \& Sobel (1987), Mookherjee \& Png (1989, 1990); Melumad \& Mookherjee, (1989)). Moreover, research into optimal income tax structures in the context of agency theory also has been unexplored, except for Mookherjee and Png (1989).

The rest of this paper is organized as follows. Section 2 sets up the basic model. Section 3 derives the optimal tax structure on the basis of the perfect information as a benchmark. Sections 4 through 6 present the model under the conditions of imperfect information. In particular, Section 4 derives the optimal tax structure under the assumption that public service has well established ethics and no corruption. Sections 5 and 6 derive optimal tax structures under the assumptions of a collusion-free case where corruption is tolerated and a collusion-proof case where corruption is reduced, respectively, through wages. Section 7 summarizes and concludes the study.

\section{Basic Model}

To set up issues for the study, let us specify a three-layer hierarchy of government-tax auditor-taxpayers. In determining the tax structure, this paper considers spending to be set exogenously, hereafter referred to as "spending constraints." Under its spending constraints, government develops a tax structure that allows it to maximize economic welfare. The tax auditor contains two types of agents - those who are ethically rigorous (incorruptible cases) and those who accept bribes (corruptible cases). 
For simplicity, taxpayers are assumed to occupy one of the two income brackets, $I_{L}$ and $I_{H}$ (where, $0<I_{L}<I_{H}$ ). Income distribution is assumed to be exogenous, with the probability density of $I_{i}, i=L, H$ set as $q_{i} \in(0,1)$, where $q_{L}+q_{H}=1$.

It is assumed that individuals do not leave each income bracket, $q_{i}$. Thus, each income bracket is assumed to include many taxpayers, allowing for consideration of typical taxpayer behaviors within each income bracket.

True income for all taxpayers is assumed to be provided exogenously. Furthermore, the income of (typical) taxpayers is private information, hereafter referred to as a "type" of taxpayer.

For simplicity, for each $i, i=L, H$, all taxpayers are assumed to spend their disposable income on one kind of private consumption. If the level of private consumption of type $i$ is $X_{i}$, and the reporting of $I_{i}$ for the statutory income tax $T_{i}$ (where $0<T_{i}<I_{i}, i=L, H, T_{H}>T_{L}>0$ ), the

value of $x_{i}$ specifically will be either $\bar{x}_{i}, \hat{x}_{i}$, or $\tilde{x}_{i}$. If income is reported properly, $\bar{x}_{i}=I_{i}-T_{i}, i=L, H$;

if income is reported fraudulently,

$\hat{x}_{i}=I_{i}-T_{j}-F, i, j=L, H, j \neq i$.

Alternatively, if the fraudulent report is not discovered,

$\tilde{x}_{i}=I_{i}-T_{j}, i, j=L, H, j \neq i$.

Together with the fact that $T_{H}>T_{L}$, since $F>0$, it is irrational for low income earners to make fraudulent reports. Thus for (3), only $\hat{x}_{H}=I_{H}-T_{L}-F$, and for (4), only $\tilde{x}_{H}=I_{H}-T_{L}$ are possible. In order to derive the optimal tax structure, the utility function is defined as

$u_{i}=\ln \left(x_{i}\right)$.

Hereafter, the right-hand sides of (2)-(4) are used for $X_{i}$.

Utilitarian economic welfare, $W$, is defined by

$W=q_{L} \ln \left(I_{L}-T_{L}\right)+q_{H} \ln \left(I_{H}-T_{H}\right)$.

Based on the traditional framework of optimal income tax theory, government must raise funds through income taxes to pay exogenous expenses. Government must determine a tax structure $\left(T_{L}, T_{H}\right)$ that

maximizes utilitarian economic welfare spending under these spending constraints.

\section{Optimal Tax Structure under Perfect Information}

As a benchmark for later comparison, this paper analyzes the optimal income tax structure under the assumption of perfect information. When all information is perfectly available, government has no organizational raison d'etre to employ tax auditors. If $R$ is exogenous spending, government's concern is to determine a tax structure $\left(T_{L}, T_{H}\right)$ that maximizes $W$ under the constraints of

$q_{L} T_{L}+q_{H} T_{H}=R$.

Here if (1) or (4) is substituted into an objective function, the following is obtained:

$W=q_{L} \ln \left(I_{L}-T_{L}\right)+\left(1-q_{L}\right) \ln \left(I_{H}-\left(\frac{R-q_{L} T_{L}}{1-q_{L}}\right)\right)$

Solving the first level conditions for $T_{L}$ gives

$-\frac{q_{L}}{I_{L}-T_{L}}+\left(1-q_{L}\right) \frac{\frac{q_{L}}{1-q_{L}}}{I_{H}-\left(\frac{R-q_{L} T_{L}}{1-q_{L}}\right)}=0$.

Considering that $q_{L}>0$ and $\left(1-q_{L}\right) I_{H}+q_{L} T_{L}>\left(1-q_{L}\right) T_{H}+q_{L} T_{L}=R$, solving for $T_{L}$ gives 
$T_{L}=R-\left(1-q_{L}\right)\left(I_{H}-I_{L}\right)$.

Substituting these results into the constraint function gives

$T_{H}=R+q_{L}\left(I_{H}-I_{L}\right)$.

Summarizing the above results, with the definition of $\Delta I=I_{H}-I_{L}$, gives

Proposition 1: The optimal income tax under conditions of perfect information is $T_{L}=R-q_{H} \Delta I ; T_{H}=R+q_{L} \Delta I$.

From Proposition 1, we see circumstances in which, regardless of the type, the optimal income tax is an increasing function of $R$. Furthermore, with regard to income gaps $(\Delta I), T_{L}\left(T_{H}\right)$ is a decreasing

(increasing) function. Also, rewriting formulas (10) and (11) makes it apparent that the gross income $\left(q_{H} I_{H}+q_{L} I_{L}\right)$ is a decreasing function.

Since disposable income for any type is given by

$I_{i}-T_{i}=q_{H} I_{H}+q_{L} I_{L}-R, i=L, H$,

after-tax utility is the same in equilibrium. In other words,

$u_{L}=u_{H}=\ln \left(q_{H} I_{H}+q_{L} I_{L}-R\right)$.

Thus, for exogenous spending, in general, if the gross income is large enough (in other words, if $R_{R}<q_{H} I_{H}+q_{L} I_{L}$ ), after-tax utility for either type of taxpayer will be positive $\left(u_{i}>0\right)$. In addition, in equilibrium, the level of economic welfare will also be positive (in other words, $\left.W=q_{L} u_{L}+\left(1-q_{L}\right) u_{H}\left(=\ln \left(\left(1-q_{L}\right) I_{H}+q_{L} I_{L}-R\right)\right)>0\right)$.

\section{Incentives and Penalties}

Henceforth, we consider the case of types with imperfect information (i.e., income is imperfectly captured). In particular, given that auditors do not always take bribes, we consider the case in which they act ethically.

In general. if the declared income is $i=L, H$, and if the probability of a tax investigation of this declared income is shown by $p_{i}$, since it is irrational that a type $\mathrm{L}$ taxpayer under this model should make a false claim, tax investigations should be limited to taxpayers who declare low incomes. Hereafter, the probability of investigation (for taxpayers declaring low incomes) is simply denoted as $p$. In this case, the compatible incentive conditions for type $\mathrm{H}$ are

$\ln \left(I_{H}-T_{H}\right) \geq p \ln \left(I_{H}-T_{L}-F\right)+(1-p) \ln \left(I_{H}-T_{L}\right)$,

where $F \geq T_{H}-T_{L}$ is the penalty for a false declaration. Left-hand side of (14) shows the utility for a

type $\mathrm{H}$ taxpayer who has made a rational declaration. On the other hand, its right-hand side shows the monitoring risk of probability $p$ of a type $\mathrm{H}$ taxpayer's expected utility in making a fraudulent declaration.

Solving the above for $p$ gives

$p \geq \frac{\ln \left(I_{H}-T_{L}\right)-\ln \left(I_{H}-T_{H}\right)}{\ln \left(I_{H}-T_{L}\right)-\ln \left(I_{H}-T_{L}-F\right)}$.

Since the right-hand side is positive, $p$ must be quite large to satisfy the constraints on incentive compatibility. Here placing

$$
\tilde{p}=\frac{\ln \left(I_{H}-T_{L}\right)-\ln \left(I_{H}-T_{H}\right)}{\ln \left(I_{H}-T_{L}\right)-\ln \left(I_{H}-T_{L}-F\right)}
$$

and calculating the relationship with $F$ gives

$$
\partial \tilde{p} / \partial F=-\frac{\ln \left(I_{H}-T_{L}\right)-\ln \left(I_{H}-T_{H}\right)}{\left(\ln \left(I_{H}-T_{L}\right)-\ln \left(I_{H}-T_{L}-F\right)\right)^{2}\left(I_{H}-T_{L}-F\right)}<0 .
$$

Hence, $\tilde{p}$ is a decreasing function of $F$.

Regarding $p$, which satisfies the constraints on incentive compatibility, particularly where $F=T_{H}-T_{L}$, an exhaustive survey (i.e., $p=1$ ) where $F>T_{H}-T_{L}$ includes a sample survey (i.e., $p \in(0,1])$. This means that in the former case, the penalty for tax evasion is not sufficiently "punitive." 
$<$ Figure 1 about here $>$

On the basis of Figure 1, the following lemma holds.

Lemma 1: If $F=T_{H}-T_{L}$, then $p=1$.

Hereafter, we analyze government's decisions on the basis of Lemma 1 . In addition to conventional spending $\mathrm{R}$, government must also pay the increased cost of conducting more tax investigations. For the latter case, since only the type distribution is known when budgetary decisions are made, government must commit to the cost of fully investigating type $\mathrm{H}$ taxpayers. However, since only type $\mathrm{L}$ taxpayers are low-income taxpayers, an investigation cost of $q_{L} C$ is sufficient. For simplicity, the

probability of type $L$ is set at less than $1 / 2$ to ensure the feasibility of an incentive compatible tax investigation. (Note 1 ) The optimal tax rate is the solution of the following problem. In other words,

\section{$\operatorname{Max} W$}

$\left\{T_{L}, T_{H}\right\}$

s.t. $\quad q_{L} T_{L}+\left(1-q_{L}\right) T_{H}=R+\left(1-q_{L}\right) c$

Here rewriting the constraining equation as $T_{L}=\frac{R+\left(1-q_{L}\right)\left(c-T_{H}\right)}{q_{L}}$ and substituting into the objective function, determining the first level conditions for $T_{H}$ gives

$$
-q_{L} \frac{\frac{1-q_{L}}{q_{L}}}{I_{L}-\left(\frac{R+\left(1-q_{L}\right)\left(c-T_{H}\right)}{q_{L}}\right)}-\frac{1-q_{L}}{I_{H}-T_{H}}=0 .
$$

Solving the above for $T_{H}$, where $1-q_{L}>0$, gives

$T_{H}^{*}=R+q_{L} \Delta I+\left(1-q_{L}\right) c$.

Substituting these results into the constraining equation gives

$T_{L}^{*}=R-\left(1-q_{L}\right) \Delta I+\left(1-q_{L}\right) c$.

Under the structure of the parameters of Lemma 1, the above can be summarized in the following form as a proposition.

Proposition 2: The optimal tax rate under asymmetrical information is given as

$T_{H}^{*}=R+q_{L} \Delta I+\left(1-q_{L}\right) c ; T_{L}^{*}=R-\left(1-q_{L}\right) \Delta I+\left(1-q_{L}\right) c$.

Since economic welfare in equilibrium is given by

$W=\ln \left(\left(1-q_{I}\right) I_{H}+q_{I_{i}} I_{I}-R-\left(1-q_{L}\right) c\right)$,

where $R+\left(1-q_{L}\right) c<q_{H} I_{H}+q_{L} I_{L}, W>0$.

\section{Discipline and Corruption}

Based on Proposition 2, the amount of tax evaded is given by $T_{H}^{*}-T_{L}^{*}=\Delta I$. Hereafter, we consider the conventional case of transfers hetween parties. In other words, the distribution of $\Delta I$ is given exogenouslv and the ratio of taxpayers is $\sigma \in(0,1)$. Here for $\Delta I$, taxpayers will offer bribes to investigators in the amount of $(1-\sigma) \Delta I$

$<$ Figure 2 about here>

$\alpha$ shows the level of penalties for "corruption charges," and $\theta$ represents the likelihood of that corruption being discovered. Where the investigator is a neutral risk, the expected payoff $A^{e}$ can be shown as

$A^{e}=\theta((1-\sigma) \Delta I-\alpha)+(1-\theta)(1-\sigma) \Delta I$.

Figure 2 shows that where $\alpha<(1-\theta) \Delta I / \theta$, there is corruption. (Note 2)

Figure 3 shows the penalties and distribution ratios that fit these conditions. In other words, the possibility $(\sigma, \alpha)$ lies within the range of I, II in Figure 3, and corruption is established in the region below the straight line descending to the right (Region I), and no corruption is established in Region II above the straight line. 
$<$ Figure 3 about here $>$

Now let us examine how economic welfare and financial conditions affect the established parameters for corruption. In doing so, the utility for type $\mathrm{H}$ takes into consideration the amount of bribe, given as

$u_{H}^{\prime}=\ln \left(I_{H}-T_{L}^{*}-(1-\sigma) \Delta I\right)$.

The additional burden of type $\mathrm{H}$ is established by

$T_{L}^{*}+(1-\sigma) \Delta I<T_{H}^{*}$

with economic welfare $W$ increasing in equilibrium. In other words, in terms of utilitarian economic welfare as measured by utility of taxpayers, collusion would improve social conditions.

On the other hand, while tax revenues are given as $T_{L}^{*}+\left(1-q_{L}\right) \theta \alpha$ in equilibrium, if the above

$\alpha<(1-\theta) \Delta I / \theta$ is established and if tax revenues decrease in equilibrium, they will not be sufficient to cover expenditures, even taking into account the payment of penalties.

\section{Wages as a Strategy to Prevent Corruption}

In this paner the incentive for corruption can be defined as the relationship between bribes and penalties. Therefore, where $\alpha<(1-\theta) \wedge I / A \quad$ oovernment could theoretically reduce corruption by providing $s=q_{H}((1-\sigma)(1-\theta) \Delta I / \theta-\alpha)$ in compensation to auditors. In this case, the issue

for government is

\section{$\underset{\left\{T_{L}, T_{H}\right\}}{\operatorname{Max} W}$}

s.t. $q_{L} T_{L}+\left(1-q_{L}\right) T_{H}=R+\left(1-q_{L}\right) c+s$

Rewriting the constraining equation as $T_{L}=\frac{R+s+\left(1-q_{L}\right)\left(c-T_{H}\right)}{q_{L}}$ and substituting into the objective function, solving for the first order conditions of $T_{H}$, where $1-q_{L}>0$, gives

$$
\left(1-q_{L}\right) \frac{\frac{1-q_{L}}{q_{L}}}{I_{L}-\left(\frac{R+\left(1-q_{L}\right)\left(c-T_{H}\right)+S}{q_{L}}\right)}-\frac{q_{L}}{I_{H}-T_{H}}=0 .
$$

Solving this for $T_{H}$ gives

$T_{H}^{*}=R+q_{L} \Delta I+\left(1-q_{L}\right) c+s$.

Substituting these results into the constraining equation gives

$T_{L}^{*}=R-\left(1-q_{L}\right) \Delta I+\left(1-q_{L}\right) c+s$.

The above results can be summarized as Proposition 3:

Proposition 3: The optimal income tax required to assure revenue $R$ is given by

$T_{H}^{*}=R+q_{L} \Delta I+\left(1-q_{L}\right) c+s ; T_{L}^{*}=R-\left(1-q_{L}\right) \Delta I+\left(1-q_{L}\right) c+s$

From Proposition 3, economic welfare is

$W^{*}=\ln \left(\left(1-q_{L}\right) I_{H}+q_{L} I_{L}-R-\left(1-q_{L}\right) c-s\right)$.

The table below summarizes the results of Propositions 2 and 3 .

$<$ Table 1 about here $>$

Where

$W^{*}=\ln \left(q_{H} I_{H}+q_{I} I_{L}-R-q_{H} c\right)$

$W^{++}=q_{H} \ln \left(q_{H} I_{H}+q_{L} I_{L}-R-q_{H} c+\sigma \Delta I\right)+q_{L} \ln \left(q_{H} I_{H}+q_{L} I_{L}-R-q_{H} c\right)$

$W^{+}=\ln \left(q_{H} I_{H}+q_{L} I_{L}-R-q_{H} c-s\right)$. 
Comparisons of welfare under imperfect information are as follows (economic welfare in the comparison below does not consider the welfare of tax auditors). Since economic welfare for compliant cases is $W^{*}=\ln \left(q_{H} I_{H}+q_{I} I_{L}-R-q_{H} C\right)$, and for non-compliant/collusion-proof cases is

$W^{+}=\ln \left(q_{H} I_{H}+q_{L} I_{L}-R-q_{H} C-S\right)$, the former is more socially desirable than the latter. On the other hand, for non-compliant/collusion-proof cases, the utility of bribery exceeds the compliant case, implying that this is the most desirable of the three cases. (Note 3)

Thus, under imperfect information, accepting bribes would be the most socially desirable, but this is the only case in which a fiscal deficit occurs.

Proposition 4: For an optimal tax structure with no fiscal deficit, $W^{+}<W^{*}$.

\section{Conclusion}

This paper derived the optimal tax structure for the hierarchy of government-tax agency-taxpayers and compared economic welfare under four cases: (1) perfect information, (2) imperfect information where there are corruption issues, (3) corruption exists and is accepted, and (4) in the case of reducing corruption.

This analysis found that case (3) was optimal. The major policy implication of this study is that it is not necessarily desirable to increase wages of civil servants as an anticorruption measure. This implication is made clear by observing the worsened conditions produced by case (4). In other words, even if government can reduce corruption by improving civil servants' pay, obtaining funds to do so by raising the income tax will worsen economic welfare, based on the optimal tax structure.

\section{References}

Border, K., \& Sobel, J. (1987). Samurai accountant: A theory of auditing and plunder. Review of Economic Studies. 54. 525-540. http://dx.doi.org/10.2307/2297481

Melumad, N.D., \& Mookherjee, D. (1989). Delegation as commitment: The case of income tax audits, RAND Journal of Economics. 20-2. 139-163. http://dx.doi.org/10.2307/2555686

Mookherjee, D., \& Png, I. (1989). Optimal auditing, insurance and redistribution. The Quarterly Journal of Economics. 104-2. 399-415.

Mookherjee, D., \& Png, I. (1990). Enforcement costs and the optimal progressivity of income taxes. Journal of Law, Economics, and Organization. 6-2. 411-431.

Myrdal, G. (1968). Asian Drama: An inquiry into the poverty of nations, London, Allen Lane the Penguin Press.

Reinganum, J., \& Wilde, L. (1985). Income tax compliance in a principal agent framework. Journal of Public Economics. 26. 1-18. http://dx.doi.org/10.1016/0047-2727 (85)90035-0

Singh, K.J. (2008). On tax evaders and corrupt auditors. The Journal of International Trade \& Economic Development. 17-1. 37-67.

Virmani, A. (1987). Tax evasion, corruption and administration: Monitoring the people's agent under symmetric dishonesty. Discussion Paper 271, Development Research Division, The World Bank.

\section{Notes}

Note 1. Although an abstraction in this paper, the budget allocation is wasted where the type L distribution is smaller than $1 / 2$.

Note 2. For distribution rate $\Delta I$, solving for the range of $\sigma$ given by $\sigma \in(0,1]$ and $A^{e}(\sigma) \geq 0$, as long as $\Delta I>\theta \alpha, \sigma \in(0,1-(\theta \alpha / \Delta I)]$, and thus there is room in this range for negotiation in determining $\sigma$. This paper considers this problem in the abstract, as a conventional parameter of the distribution ratio.

Note 3. This economic welfare of

$$
W^{++}=q_{H} \ln \left(q_{H} I_{H}+q_{L} I_{L}-R-q_{H} c+\sigma \Delta I\right)+q_{L} \ln \left(q_{H} I_{H}+q_{L} I_{L}-R-q_{H} c\right) \text { will exceed the economic }
$$

welfare under conditions of perfect information of $q_{H} \ln \left(q_{H} I_{H}+q_{L} I_{L}-R\right)+q_{L} \ln \left(q_{H} I_{H}+q_{L} I_{L}-R\right)$, where income inequality $\Delta I$ is sufficiently large. 
Table 1. Optimal Tax Structure

\begin{tabular}{|l|l|l|l|}
\hline \multirow{2}{*}{} & \multirow{2}{*}{ Compliant } & Non-compliant \\
\cline { 3 - 4 } & & Collusion-free & Collusion-proof \\
\hline$T_{H}$ & $R+q_{L} \Delta I+q_{H} C$ & $R+q_{L} \Delta I+q_{H} C$ & $R-q_{L} \Delta I+q_{H} C+S$ \\
\hline$T_{L}$ & $R-q_{H} \Delta I+q_{H} C$ & $R-q_{H} \Delta I+q_{H} C$ & $R-q_{H} \Delta I+q_{H} C+S$ \\
\hline Welfare & $W^{*}$ & $W^{++}$ & $W^{+}$ \\
\hline Finances & Balanced & Deficit & Balanced \\
\hline
\end{tabular}

E3

E2

E1

PF

PAC

$\mathrm{AD}$

$p_{H}$

Figure 1. Monitoring Probability

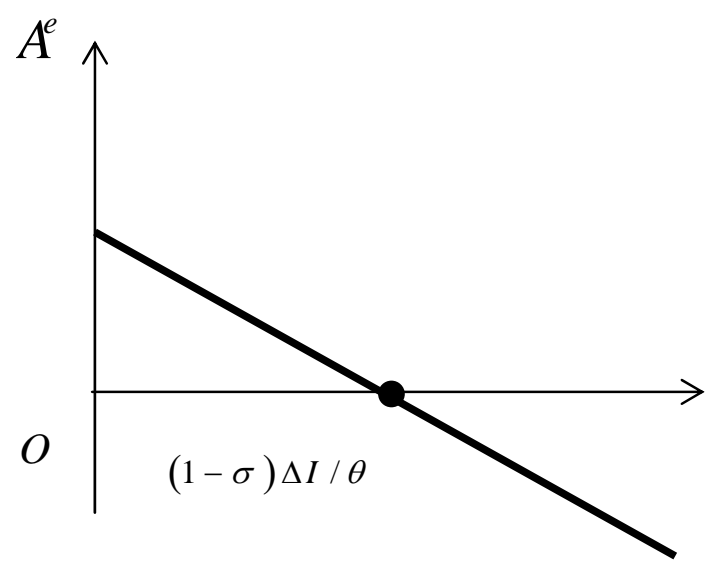

Figure 2. Conspiracy and Corruption Charges 


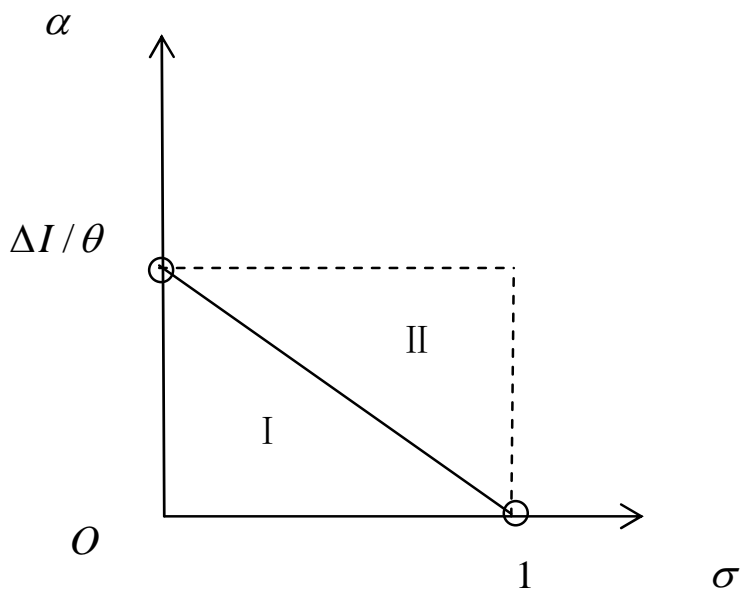

Figure 3. Corruption Charges and Bargaining Power 